\title{
Altas habilidades/superdotação na perspectiva da inclusão escolar: experiências fenomenológicas a partir da implementação de diretrizes municipais
}

High abilities/giftedness in the perspective of school inclusion: phenomenological experiences from the implementation of municipal guidelines

Altas habilidades/superdotación en la perspectiva de la inclusión escolar: experiencias fenomenológicas a partir de la implementación de directrices municipales

\footnotetext{
* Maria Amelia Barcellos Fraga

Mestranda pela Universidade Federal do Espírito Santo, Vitória, Espírito Santo, Brasil. mabfraga@vitoria.es.gov.br - http://orcid.org/0000-0002-3665-7237
}

\section{** Vitor Gomes}

Professor doutor na Universidade Federal do Espírito Santo, Vitória, Espírito Santo, Brasil. vitor.gomes@ufes.br - http://orcid.org/0000-0003-3388-1054

Recebido em 11 de junho de 2018

Aprovado em 23 de janeiro de 2019

Publicado em 06 de maio de 2019

\section{RESUMO}

Este artigo possui como objetivo apresentar as contribuições do método fenomenológico para o professor do Atendimento Educacional Especializado (AEE) em Altas Habilidades/Superdotação (AH/SD). Teoricamente, referencia-se em Holanda (2003), Merleau-Ponty (2011), Perez (2009), Renzulli (2014), Virgolim (2010) e outros. Em termos metodológicos, trata-se de pesquisa fenomenológica eidética, cujo intuito é a elucidação do vivido. Utiliza como instrumentos: Diário de campo, Versão de sentido e conversas não diretivas. Como resultados e discussões, evidencia que urge a necessidade de revisão de estratégias e instrumentos produzidos a partir de lógica psicométrica/quantitativa que serviram exclusivamente para produção de estereótipos sobre a pessoa com AH/SD. Nas conclusões, indica a necessidade de compreensão dos educandos em seus aspectos multidimensionais, numa demonstração de que é necessário entendê-los qualitativamente como indivíduos, em suas particularidades, numa atitude aberta à inclusão escolar.

Palavras-chave: Altas habilidades/superdotação; Educação especial; Fenomenologia. 


\section{ABSTRACT}

This article aims to present the contributions of the phenomenological method to the teacher of the Specialized Educational Attendance (AEE) in High Abilities /Giftedness (AH/SD). Theoretically, it is referenced in Holanda (2003), Merleau-Ponty (2011), Perez (2009), Renzulli (2014), Virgolim (2010) and others. In methodological terms, it is an eidetic phenomenological research, whose purpose is the elucidation of the lived. It uses as instruments: field diary, sense version and non-directive conversations. As results and discussions, it is evident that it is urgent to review strategies and instruments produced from psychometric / quantitative logic that exclusively served to produce stereotypes about the person with AH / SD. In the conclusions, it indicates the need to understand the students in their multidimensional aspects, in a demonstration that it is necessary to understand them qualitatively as individuals, in their particularities, in an attitude open to school inclusion.

Keywords: High abilities/giftedness; Special education; Phenomenology.

\section{RESUMEN}

Este artículo tiene como objetivo presentar las contribuciones del método fenomenológico al profesor del Atendimiento Educativo Especializado (AEE) en Altas Habilidades/Superdotación (AH/SD). Teóricamente, se refiere en Holanda (2003), MerleauPonty (2011), Perez (2009), Renzulli (2014), Virgolim (2010) . y otra. En términos metodológicos, se trata de una investigación fenomenológica eidética, cuyo propósito es la elucidación de lo vivido. Utiliza como instrumentos: Diario de campo, Versión de sentido y conversaciones no directivas. Como resultados y discusiones, evidencia que urge la necesidad de revisión de estrategias e instrumentos producidos a partir de lógica psicométrica/cuantitativa que sirvieron exclusivamente para la producción de estereotipos sobre la persona con AH/SD. En las conclusiones, indica la necesidad de comprensión de los educandos en sus aspectos multidimensionales, en una demostración de que es necesario entenderlos cualitativamente como individuos, en sus particularidades, en una actitud abierta a la inclusión escolar.

Palabras clave: Altas Habilidades/superdotación; Educación especial; La fenomenología.

\section{Introdução}

Ingressando num Mestrado Profissional em Educação, fui apresentada a perspectivas de compreensão da realidade (que até então) eram desconhecidas em minha prática profissional. Destaco a fenomenologia, que a partir de minha imersão e pertencimento, me induziram ao sentimento de que foi retirada uma venda de meus olhos.

Desta forma, o trabalho em conjunto com meu orientador, possibilitou-me o conhecimento do método fenomenológico de pesquisa em seus aspectos procedimentais e concepções particulares. 
As reflexões deste trabalho foram constituídas em concomitância com a elaboração do projeto de pesquisa de minha dissertação, que, atualmente, se encontra em fase pósqualificação, em aprofundamento da revisão de literatura e coleta de dados.

Este artigo ${ }^{1}$ foi criado sob a supervisão do meu professor orientador, que me ensejou a construí-lo a partir do entrelaçamento com a fenomenologia, indicando-me que minhas vivências eram dados relevantes para descrição da experiência do vivido.

Possuímos como objetivo a apresentação de contribuições do método fenomenológico para o professor do Atendimento Educacional Especializado (AEE) em Altas Habilidades/Superdotação (AH/SD). Para isto, "ilustramos" este trabalho com vivências, aspectos teóricos, falas e entrelaçamentos realizados em capacitação ministrada com professores de uma rede municipal de ensino que atuam com este público-alvo.

Para o alcance do intuito organizamos o artigo em quatro partes. Na primeira delas, apresentamos os "Aspectos históricos e conceituais" concernentes às AH/SD e à Fenomenologia. Em sequência: "A Fenomenologia do vivido: atravessamentos a partir da implementação de diretrizes operacionais municipais", entrelaça as minhas experiências eidéticas ao local que habito.

$\mathrm{Na}$ terceira parte, "Contribuições da fenomenologia ao professor de atendimento educacional especializado (AEE), evidenciamos aspectos teóricos-conceituais inerente a abordagem fenomenológica que desvelam uma ressignificação desconstrutora acerca de concepções ligadas a modelos cognitivistas.

A última parte, "A vivência fenomenológica na prática do professor especializado", entrelaça as diretrizes operacionais do município para inclusão de educandos nas AH/SD e o método fenomenológico nas práticas e experiências do professor especializado junto aos educandos encaminhados para o AEE.

\section{Aspectos históricos e conceituais}

Um dos aspectos constituintes nos estudos sobre AH/SD refere-se à associação entre o desenvolvimento mental e a inteligência. Nesse sentido, Perez (2009) enfatiza que seus indicadores de manifestação refletem essa sincronia. Para Rangni e Costa (2011), não há definição precisa sobre o que é inteligência e, no que se que refere às $A H / S D$, o caminho é semelhante.

${ }^{1}$ Com elementos integrantes de meu projeto de pesquisa 
De acordo com Bock, Furtado e Teixeira (2002), as indagações e reflexões mais consistentes acerca do ato de pensar se realizaram na Grécia antiga e foram concomitantes ao surgimento de ideias psicológicas sobre a individualidade. Segundo os autores, os primórdios da reflexão desse tema podem ser encontrados por volta do ano 700 a.C, com a superação das crenças em mitos e deuses existentes, a partir da predominância do pensamento filosófico, caracterizado por indagações e questionamentos, cujo intuito era explicar fenômenos da realidade a partir de uma racionalidade, em oposição ao mitológico e, assim, servindo como base, séculos mais tarde, para a Psicologia.

Com o advento dos estudos acerca da inteligência e, consequentemente, de modelos educacionais para identificação e atendimento nas AH/SD (ALENCAR; FLEITH, 2001; PEREZ, 2009; RENZULLI, 2014; VIRGOLIM, 2010), o conceito de unidimensionalidade², provido pelos testes padronizados, foi substituído pelo de multidimensionalidade ${ }^{3}$. Esses estudos indicam que o debate entre diferentes concepções de AH/SD evidencia sua complexidade, o que ressalta ser possível uma compreensão holística e distanciada da visão unidimensional associada ao conceito de $\mathrm{QI}^{4}$, predominante no início do século XX.

Conforme Zaia, Nakano e Peixoto (2018), as diversas formas de identificação das AH/SD têm sido amplamente discutidas na literatura científica, e os resultados desses estudos compreendem as AH/SD como um fenômeno multidimensional, incluindo atributos que vão além do âmbito intelectual. Assim, certas visões restritas ao campo educacional foram substituídas por outras, em aspectos multidimensionais, que envolvem Biologia, Psicologia, emoções e o social/histórico/cultural.

Essa ampliação no modo de olhar as habilidades mentais leva autores a considerar que há necessidade da revisão dos instrumentos e estratégias educacionais para identificação das AH/SD que, para além de testes psicométricos, deve levar em conta diferentes aspectos do indivíduo na percepção de suas habilidades, desmistificando estereótipos e mitos acerca desses educandos, principalmente, no contexto escolar.

\footnotetext{
${ }^{2} \mathrm{O}$ conceito de unidimensionalidade, no contexto deste estudo, é considerado como uma visão limitada do fenômeno da inteligência, associado ao conceito de QI, que provém de instrumento padronizado para se dimensionar a inteligência unicamente por meio de testes psicológicos.

${ }^{3}$ A concepção de multidimensionalidade considera mais de uma dimensão para se observar o fenômeno da inteligência e envolve aspectos biológicos, psicológicos, emocionais, sociais, históricos e culturais.

${ }^{4}$ Quociente Intelectual (QI) trata-se de uma unidade de medida da inteligência também chamada de Stanford-Binet Intelligence Scale. Consta que, em 1904, o governo francês solicitou a Binet que criasse um instrumento que pudesse prever se crianças teriam sucesso nas escolas francesas. $O$ instrumento criado deu origem ao primeiro teste de QI (GAMA, apud RANGNI; COSTA, 2011, p. 2).
} 
No que concerne essas considerações, citamos Mendes (2018), cujos estudos corroboram os questionamentos sobre a inclusão escolar dos estudantes público-alvo da Educação Especial, ressaltando-a como um problema complexo a ser resolvido, desafiando o desenvolvimento teórico e sem simples soluções:

De fato, a educação que separa fisicamente os alunos é inerentemente discriminatória, desigual e, consequentemente, injusta. Por outro lado, a educação que meramente iguala, oferecendo o mesmo ensino no mesmo ambiente, também pode ser discriminatória, desigual e injusta se não responde às necessidades diferenciadas de alguns alunos. (MENDES, 2018, p. 80)

Virgolim (2010) evidencia a necessidade de programas voltados para a estimulação e enriquecimento do ambiente para crianças e jovens com AH/SD, de forma que favoreçam o desenvolvimento de suas potencialidades. Nesse sentido, vale destacar que, a partir de concepções inclusivas, é necessária a implementação de propostas pedagógicas que propiciem o desenvolvimento do talento de forma indistinta, envolvendo, assim, todos nos processos de ensino e aprendizagem.

Dentro da visão pluridimensional, os teóricos da área referem-se ao indivíduo com AH/SD não restritamente à questão da inteligência/habilidades, mas também voltados para os aspectos que envolvem a sua capacidade criativa e motivação.

Nesse contexto, em consonância com a Política Nacional de Educação Especial na Perspectiva Inclusiva,

[...] estudantes com altas habilidades/superdotação demonstram potencial elevado em qualquer uma das seguintes áreas, isoladas ou combinadas: intelectual, acadêmica, liderança, psicomotricidade e artes, além de apresentar grande criatividade, envolvimento na aprendizagem e realização de tarefas em áreas de seu interesse (BRASIL, 2008, p.11).

Apresentados os aspectos iniciais, é necessário evidenciar que, tal como em uma pintura, cuja influência se dá a partir de períodos históricos, os estudos sobre AH/SD ainda carregam predominantemente influência e conceitos arraigados de um cognitivismo catalogador do século passado. É nesse sentido, e com a intenção de sua suplantação, que se faz necessária sua compreensão a partir de outros matizes teórico-conceituais.

Nessa perspectiva, a última década do século XIX, na Alemanha, caracteriza-se pela derrocada dos grandes sistemas filosóficos tradicionais. Doravante o pensamento positivista começa a sofrer abalos a partir dos questionamentos de seus fundamentos/postulados, amparados na objetividade e neutralidade científicas e também na compreensão de um "sujeito puro" (FORGHIERI, 2004). 
Segundo Forghieri,

[...] as dúvidas quanto à existência desse 'sujeito puro' e as preocupações com o sujeito concreto em sua vida psíquica imediata passam a ter predominância nessa época, preparando o terreno para o aparecimento da Fenomenologia moderna. (FORGHIERI, 2004, p.14)

A fenomenóloga ressalta que, no início do século XX, surgem as primeiras obras sobre Fenomenologia, elaboradas por Edmund Husserl, com influências dos filósofos Franz Brentano e Wilhelm Dilthey, fato que influencia outros pensadores que deram continuidade às suas ideias, problematizando/destituindo a teorização do conhecimento da época e sua concepção da verdade pura, neutra, geral, estática e acabada.

A partir da Segunda Guerra Mundial e de conceitos de pensadores como Maurice Merleau-Ponty, a Fenomenologia sofre aproximações e influência do humanismo existencial. Nesse sentido, busca a essência dos fenômenos na existência do ser em sua imersão no mundo, em movimento num continuum espacial e temporal, captando sentidos e significações em sua vivência concreta e cotidiana.

Assim, para Forghieri (2004, p.18), "[...] a reflexão fenomenológica vai em direção ao 'mundo da vida', ao mundo da vivência cotidiana imediata, na qual todos nós vivemos, temos aspirações e agimos, sentindo-nos ora satisfeitos e ora contrariados".

Dessa forma, o método fenomenológico, a partir de sua perspectiva humanista, pode contribuir significativamente na potencialização das habilidades nos indivíduos com AH/SD e, fundamentalmente, no olhar do professor para além da lógica psicométrica ou instrumentalizadora e, por conseguinte, ele pode realizar um trabalho permeado pela lógica compreensiva da pessoa com AH/SD dentro de perspectivas favorecedoras de seu empoderamento e bem-estar.

Trata-se da utilização da Fenomenologia, em seus aspectos potencializadores, pelo professor em sua percepção acerca do outro, que desvela vivências, experiências, inserções e atravessamentos numa lógica de imbricamento. Nesse processo, deve prevalecer o pertencimento e bem estar da pessoa, transcendendo o exclusivo desenvolvimento e/ou a potencialização de sua habilidade. 


\section{A Fenomenologia do vivido: atravessamentos a partir da} implementação de diretrizes operacionais municipais ${ }^{5}$

Uma trajetória de vida é marcada pela concretude de sua existência. Seja como corpo carnal, situado num tempo/espaço, seja como sujeito histórico em movimentos que atualizam experiências do passado e que as vivenciam no presente, dentro da linha inconstante das escolhas e incertezas em relação ao futuro. Nesses movimentos, enunciam-se opções que desvelam sentidos/ significados; experiências; sentimentos cristalizados nas vivências, em um ser com/no mundo mediado pela percepção (MERLEAU-PONTY, 2011).

Mas, antes de tudo, tomo a dimensão do aqui e agora, para desvelar a consolidação de minha existência fenomenológica. Para isto, devo expressar que, depois de anos fora do universo acadêmico, no "primeiro contato" com a fenomenologia, sou envolta pelo sentimento de insegurança.

Contudo, no resgate da primeira fala de meu orientador, cujo sentido expressa o meu ser-estar-vivenciar (atual), indica que sempre fui atravessada pela fenomenologia em minha vida. Uma vez que cada experiência de sentido, percepção e compreensão são experiências fenomenológicas.

Por isto, o que produzimos, sentimos, realizamos é envolto dos processos intersubjetivos, cuja interiorização produz a experiência do vivido. Desta forma, o que iniciei (neste momento) foi o processo de apropriação teórica do que havia experienciado durante a minha vida.

Assim, a partir da fenomenologia eidética, cujo intuito é o evidenciamento do vivido (HOLANDA, 2003), desnudam-se minhas experiências/vivências em AH/SD, cujo percurso tem como ponto de partida o início deste século. Neste sentido, desvela-se meu ser/estar como psicóloga da gerência/coordenação de Educação Especial de uma rede municipal de ensino, no início da implementação dos atendimentos especializados em altas habilidades.

Esse período foi marcado por políticas de atendimento restritas à aceleração de estudos (para os educandos identificados com elevado potencial) e outros programas de atendimento para o desenvolvimento de habilidades. Em nível municipal, o Programa de

\footnotetext{
${ }^{5} \mathrm{O}$ relato está fundamentado a partir da experiência de mestranda sob a supervisão do orientador, como parte integrante do projeto de pesquisa, portanto algumas narrativas estão descritas na $1^{\underline{a}}$ pessoa do singular.
} 
Desenvolvimento da Criatividade (PDC) ensaiava seus primeiros passos em três escolas de ensino fundamental.

Em 2005, o Ministério da Educação (MEC) implantou, nas unidades da Federação e no Distrito Federal, os Núcleos de Atenção às Altas Habilidades/Superdotação (NAAH/S) ${ }^{6}$, considerados promissores para o desenvolvimento de processos formativos, fortalecimento e qualificação dos programas de atendimento.

Municipalmente, na nossa Rede pública de ensino, evidenciamos maior visibilidade à área de $\mathrm{AH} / \mathrm{SD}$ e o progressivo aumento de encaminhamentos desses educandos, resultando em um número maior de atendimentos especializados. Vivenciaram-se embaraços, mediante o sentimento de impotência dos professores para viabilizar os atendimentos a partir das diferentes habilidades/áreas de conhecimento apresentadas pelos educandos encaminhados.

Na ocasião, o MEC ainda não dispunha de política nacional oficial para atendimento ao público da modalidade. Dessa forma, a fim de otimizar os recursos existentes para o financiamento da área, envolvendo espaços, materiais, pessoas e parcerias, a gestão municipal implantou o modelo de Centro de Desenvolvimento de Talentos (CEDET) ${ }^{7}$, em parceria com a seccional estadual da Associação Brasileira para Altas Habilidades/Superdotação (ABAHSD).

Nessa época, atuava como assessora especializada e coordenadora da Coordenação de Formação e Acompanhamento à Educação Especial municipal. Contudo, depois de algum tempo, como ser-no-tempo (GOMES, 2016; 2017), outras experiências/movimentos me atravessaram na concretude da existência e, assim, a atuação na área de AH/SD ficou em suspensão por sete anos de minha vida.

Meu corpo tomou outras dimensões espaço/temporais e por quase 7 anos residi em outro Estado da Federação desenvolvendo outras experiências como psicóloga e professora do ensino superior. Tais experiências enriqueceram minha existência, agregando-me outros sentidos/significados no existir.

\footnotetext{
${ }^{6}$ Centro de Formação e Recursos (CAP, CAS e NAAHS) - Portal do MEC. (Disponível em: portal.mec.gov.br/index.php?option=com_content\&view=article\&id=17437. Acesso em: 21 abr. 2018).

7 O Centro para Desenvolvimento do Potencial e Talento (CEDET) é um centro de Educação Especial de reconhecimento internacional. Foi idealizado em 1992, na cidade de Lavras (MG) pela educadora Zenita Guenther, como um espaço físico e social estruturado para a dinamização da metodologia CEDET. (Disponível em: map.reevo.org/reports/view/810?l=pt_PT. Acesso em: 21 abr. 2018
} 
Atravessada/perpassada pelas características do existir, após esses anos residindo fora, retomo para a minha cidade natal, para a Secretaria Municipal de Educação e para a área de AH/SD, 14 anos mais tarde do início do PDC. Assumo a função de assessora especializada da Coordenação de Educação Especial, num momento de implantação das novas diretrizes operacionais para encaminhamento de educandos às AH/SD.

Os primeiros meses desse regresso à área de AH/SD foram marcados por interlocuções cristalizadas por desencontros, desafetos e muitas incertezas, cujos conflitos tornavam inviáveis os consensos e, assim, todo o processo global de trabalho e seus atravessamentos num espaço-tempo de aproximações de diretivas nacionais.

Destarte, o órgão gestor municipal delineia a necessidade de alinhamento à Política Nacional de Educação Especial na Perspectiva Inclusiva (PNEE) (BRASIL, 2008), em consonância com as diretrizes oficiais do MEC, formalizando o modelo de atendimento educacional especializado (AEE) ofertado em Salas de Recursos Multifuncionais (SRMs) para todos os educandos público da educação especial, sendo os com deficiências, com transtornos globais do desenvolvimento, com altas habilidades/superdotação.

Assim se estabelecia o conflito, pois, na opinião dos professores especializados, o órgão gestor deveria manter o modelo de desenvolvimento e atendimento dos estudantes com AH/SD de forma semelhante ao CEDET e não o proposto pelas novas instruções.

Nesse contexto, o desafio consistia em mediar desacordos a partir dos diferentes pontos de vista, buscando conduta e ações que fomentassem o conciliamento e favorecimento das inter-relações pessoais e profissionais e, dessa forma, não causassem prejuízos ao atendimento dos educandos com AH/SD.

Confesso que as emoções e os sentimentos, nos primeiros seis meses desse processo, não foram os melhores. Em muitos momentos, os ânimos se acirraram e houve fortes resistências, pois toda mudança é permeada por incertezas como num mergulho em oceano desconhecido e ameaçador. Entretanto, com a chegada dos educandos, ainda que com discordâncias, ocorre o início da flexibilização de comportamentos pelos professores e o alinhamento com novas diretrizes, a partir da crença de que é possível a realização do trabalho.

As diretrizes operacionais para encaminhamento dos educandos foram apresentadas de acordo com os documentos normativos que regem a PNEE e o AEE. Dessa forma, em nível municipal, as SRMs são localizadas em seis unidades de ensino fundamental (UEs), 
constituídas por professores especializados em AH/SD. Nessas unidades, são identificados e desenvolvidos diversos projetos de enriquecimento curricular baseados nos interesses dos educandos.

A partir daí, organizam-se fluxos de atendimentos com o esboço de instrumentos que personalizavam o AEE dos educandos encaminhados pelas UEs. Esse foi o primeiro formato do trabalho constituído que, nos três anos seguintes, se configurou pela busca de identidade do/no trabalho, cujos processos formativos foram construídos a partir das demandas evidenciadas pelos professores.

O momento é de consolidação de ações com várias mãos e pensamentos, com idas e vindas com o envolvimento de múltiplos atores. Relembrando João Cabral de Melo Neto (2018, p.1)): "Um galo sozinho não tece uma manhã, ele precisará de outros galos [...]".

A partir desses diversos braços e ações, participaram desse processo também os professores de sala comum, em formações ${ }^{8}$ teórico-práticas em $\mathrm{AH} / \mathrm{SD}$, assessorias às UEs para estudos de caso e observação direta de educandos, parcerias e visitas a outros espaços da cidade, realização de Seminários de $\mathrm{AH} / \mathrm{SD}^{9}$ e também do evento: "Encontro com famílias nas AH/SD" ${ }^{10}$, cujo objetivo é propiciar interlocução entre o órgão gestor e as UEs, professores especializados, parceiros, educandos do AEE e suas respectivas famílias.

Por último, e esperando ter apresentado os atravessamentos das vivências, emoções e políticas municipais sobre altas habilidades, é necessário destacar que, ainda que as políticas públicas no atendimento ao educando com AH/SD possuam caráter diretivo, pela via de sentido que intuímos/ compreendemos/ vivenciamos, o método da observação e identificação de altas habilidades não precisa ser diretivo; pelo contrário, deve se consistir pela abertura a uma percepção fenomenológica de compreensão do indivíduo tendo como intuito fomentar seu bem estar.

É neste percurso que os próximos tópicos caminharão.

\footnotetext{
${ }^{8}$ Realizada a terceira turma para professores de sala comum, pedagogos, coordenadores, diretores e convidados.

${ }^{9}$ Realizada a terceira edição, aberta aos concludentes do curso, comunidades escolares e convidados. 10 Realizada a segunda edição, envolvendo os educandos, as famílias, professores especializados e convidados.
} 


\title{
Contribuições da fenomenologia ao professor de atendimento educacional especializado
}

Dentro de concepções atuais acerca das AH/SD, desvelam-se compreensões holísticas e distanciadas da visão unidimensional associada ao conceito de QI. Assim, para identificação desse público, urge a necessidade de revisão de estratégias e instrumentos produzidos pelo cognitivismo ${ }^{11}$ que, a partir de lógica psicométrica/quantitativa, serve/iu exclusivamente na produção de estereótipos sobre a pessoa altamente habilidosa.

Essa ampliação instiga a consideração de diferentes aspectos do indivíduo na percepção de suas habilidades, destituindo mitos acerca desses educandos em contextos escolares ou não. Dessa forma, a concepção do sujeito com AH/SD não deve se restringir à questão da inteligência/habilidades, mas também, estender-se aos aspectos que envolvem sua capacidade criativa e de motivação (FRAGA; FREITAS, 2016).

Nas experiências de implementação das diretrizes municipais nas AH/SD, a PNEE evidencia a necessidade de compreensão dos educandos em seus aspectos multidimensionais ${ }^{12}$, em demonstração que para seu entendimento, é necessário entendêlos qualitativamente como indivíduos com particularidades.

Nesse contexto, crendo nas contribuições do método fenomenológico de pesquisa para os saberes/fazeres dos professores, e a partir do evidenciamento de "ferramentas" que instigam a percepção do docente especializado, pretendemos evidenciar concepções existencialistas favorecedoras do empoderamento e bem estar desse educando em especial.

Apontando contribuições da abordagem fenomenológica no desvelamento/compreensão/identificação desse público-alvo da educação especial, importa-nos apresentar alguns de seus fundamentos:

\begin{abstract}
A fenomenologia procura abordar o fenômeno, aquilo que se manifesta por si mesmo, de modo que não parcializa ou o explica a partir de conceitos prévios, crenças ou afirmações sobre o mesmo, enfim de um referencial teórico. Mas ela tem intenção de abordá-lo diretamente, interrogando-o, tentando descrevê-lo e procurando captar sua essência. Ela dirige-se para o fenômeno da experiência, para o dado e procura 'ver' esse fenômeno de forma que ele se mostre na própria experiência... Daí a própria nomenclatura fenomenológica - significando o discurso sobre aquilo que se mostra como é (phenomenon+"logos") (MARTINS; BICUDO, apud BRUNS, 2003, p. 70).
\end{abstract}

${ }^{11}$ Concepção com ênfase na cognição, no ato de conhecer; estuda os processos mentais, ou seja, como o ser humano conhece o mundo.

12 Biológico, psicológico e sociocultural. 
Em seguida, enumeramos características da pesquisa fenomenológica:

1. Ausência de uma compreensão prévia do fenômeno, ou seja, inicia-se o trabalho interrogando o fenômeno. 2. A situação da pesquisa não é definida pelo pesquisador, mas pelos próprios sujeitos investigados. 3. O investigador se pauta pelo sentido (MARTINS; BICUDO, apud HOLANDA, 2003, p. 49).

2.

Em síntese, buscando descrever a atitude do sujeito-pesquisador com base na pesquisa fenomenológica:

[...] uma pesquisa fenomenológica deve buscar acessar a essência do fenômeno estudado com o intuito de poder ser posteriormente generalizado (dado que estamos nos referindo à experiência humana). Esta essência - o eidos, descrito por Husserl - pode ser alcançada a partir de um método que contemple três elementos fundamentais para se falar em pesquisa fenomenológica.

O primeiro desses elementos é a redução fenomenológica ou abstenção de juízos que deve ter o pesquisador sobre o tema pesquisado, permitindo-lhe 0 acesso aos significados puros do sujeito; o segundo elemento é a intersubjetividade ou relação que se estabelece entre sujeito-pesquisador e sujeito-pesquisado, seus conteúdos e envolvimentos decorrentes desta relação, e o terceiro elemento é o retorno ao vivido ou retomada do 'mundo da vida' do sujeito-pesquisado através do seu depoimento (HOLANDA, 2003, p. 52-53).

Aqui, a denominação pesquisador, como propõe Gomes (2012), é utilizada como sinônimo daquele que observa antes de uma intervenção, aplicando-se a professores, psicólogos e outros profissionais.

Nesse sentido, num ato de desvelamento, é necessário iniciarmos pela redução fenomenológica ou abstenção de juízos, a partir da busca do dado/registro qualitativo do fenômeno (aquilo que se manifesta por si mesmo), no caso o educando nas AH/SD, concebendo que a compreensão desse indivíduo é iniciada a partir de sua identificação. Para que isso seja possível, o que temos como instrumento é a percepção: ela é o fundo sobre o qual todos os atos se destacam (MERLEAU-PONTY, 2011).

\section{A vivência fenomenológica na prática do professor especializado}

Apresentados os aspectos teórico-filosóficos, descreveremos as diretrizes operacionais municipais em relação ao $\mathrm{AEE}$, bem como, de maneira imbricada, as contribuições do método fenomenológico para o trabalho de professores especializados, tomando por base a fenomenologia eidética, cujo intuito é o evidenciamento do vivido (HOLANDA, 2003).

Para isto, realizamos encontros formativos na perspectiva fenomenológica com os professores do AEE (das unidades de ensino da rede municipal) em parceria com a 
Universidade. Nesse espaço/tempo, metodologicamente, apresentamos aos docentes três instrumentos comuns às pesquisas fenomenológicas e indicamos suas possibilidades de emprego com seu público-alvo. Foram eles: Conversas não diretivas, Diário de campo e Versão de sentido, que se trata do registro realizado após a vivência de uma experiência de sentido (AMATUZZI, 2001).

Desta forma, evidenciaremos os envolvimentos existenciais, expressos por falas (advindas dos encontros) e, a partir dessas, a contribuição da fenomenologia para suas práticas profissionais em conformidade com a perspectiva das diretrizes municipais.

Iniciando a descrição, é preciso externar que, em conformidade com a PNEE (BRASIL, 2008), o AEE é ofertado no contraturno escolar, SRMs, equipadas com materiais pedagógicos diversificados, computador, internet, entre outros, além de realizar parcerias e visitas monitoradas em escolas da ciência, cultura e tecnologias, planetário, galerias, museus, parques, universidades, e em outros espaços da cidade.

Também podem ser utilizados outros espaços/tempos das UEs, além das SRMs; dentre eles: biblioteca, laboratório de informática e sala multiuso. Para os educandos identificados com $\mathrm{AH} / \mathrm{SD}$, as atividades de enriquecimento curricular têm o caráter de suplementação e podem ser organizadas ora individualmente, ora em grupos, visando serem vivenciadas de formas diversificadas e desafiadoras.

Para se proceder ao encaminhamento ao $\mathrm{AEE}$, os professores de classe comum realizam observação direta e continuada do educando em sala de aula e no contexto escolar, identificando seu alto potencial em alguma(s) área(s) de conhecimento ou aspecto(s) do comportamento e, em seguida, elaboram um relatório descritivo registrando esses dados coletados sobre o educando identificado. O relatório é disponibilizado para que os professores especializados de AH/SD promovam a avaliação pedagógica para desvelamento/compreensão/identificação de habilidades e interesses dos estudantes e organizar os atendimentos junto às famílias.

Para subsidiar a atuação pedagógica na área, utiliza-se autores como Virgolim (2007), Fleith (2007) e as "Ferramentas para pensar" de Edward de Bono, assim como diversos sites de buscas e pedagógicos, entre outros aportes que se fizerem necessários.

Por um período estimado de um ano letivo, no $A E E$, procedemos à organização de programa de enriquecimento curricular, no qual, realizamos entrevistas com o educando e sua família, inicialmente, buscando perceber e registrar os aspectos observados por eles 
sobre suas habilidades, interesses e comportamentos. Ainda realizamos atividades exploratórias com base no relatório descritivo do professor de sala comum, visando a evidenciar, com maior sentido/significado, sua percepção/olhar sobre este educando, especialmente.

Em seguida, constituímos com o educando projeto(s) de enriquecimento que atendam às suas necessidades para produção de conhecimentos, por meio de roteiros de pesquisas, entrevistas a terceiros, visitas monitoradas, experimentos, criação de jogos e artes, entre outras possibilidades que podem ser usadas como estratégias pedagógicas favorecedoras à sua imaginação, empoderamento e bem-estar.

Dando continuidade ao processo de avaliação pedagógica, ao final de cada ano letivo, são identificados, no Censo Escolar com AH/SD, os educandos que, efetivamente, demonstraram as habilidades identificadas, ou outras de seu interesse, com o professor especializado e outros pares, por meio das suas experiências e das trocas/relações vivenciadas no programa de enriquecimento, com originalidade e envolvimento nas produções da sala de recursos. Como podemos perceber, todo esse processo é registrado ao longo das atividades e vivências desenvolvidas, por todos os envolvidos, e sistematizado em um plano de trabalho pedagógico de cada educando, para ser publicizado entre eles, as escolas e suas respectivas famílias.

Vale registrar que, ao longo do processo, alguns educandos encaminhados não apresentam de forma efetiva as habilidades inicialmente identificadas em sala de aula, com envolvimento para problematizá-las ou aprofundá-las, como também não despertam ou se envolvem com outras produções realizadas nas relações vivenciadas/fomentadas no programa, junto aos pares, professor especializado ou parceiros.

Alguns deles não se identificam e deixam o programa; outros se mantêm, mas não são identificados no Censo Escolar com AH/SD. Partimos do princípio de que, em outros momentos, eles poderão demonstrar tais características em alguma área de interesse... ou não. Mas, sem dúvida, as experiências serão um ganho em suas vidas. Vimos no processo, dinamismo constituído de intensas relações, vivências, trocas e percepções, com idas e vindas em diferentes espaços-tempos, instituindo relações fenomenologicamente existenciais.

Apresentados os contextos de atendimento, de acordo com as diretrizes operacionais municipais, e com o intuito da apresentação do entrelaçamento entre instrumentos da 
fenomenologia e sua contribuição ao professor especializado, resgatamos a fala de uma das professoras (expressa em um dos encontros) indicando que, o professor do AEE, nos atendimentos iniciais com seu educando é constituído de ideias preconcebidas acerca deste.

A partir do relato, destacamos a importância do registro dia a dia, sobretudo nos primeiros contatos com os educandos. Esse é um procedimento necessário para realização de uma epoché/redução fenomenológica. Ou seja: o afastamento existencial diante da experiência visualizada para perceber o fenômeno como ele é.

Neste sentido, indicamos o uso do Diário de Campo, no qual o professor especializado registrará, de forma detalhada, os comportamentos, gestos, olhares do educando do $A E E$, para descrever as vivências, sem qualquer emissão interpretativa, procurando evidenciar o "desenho" do que se observa, num sublinhamento diante aos diversos acontecimentos concomitantes.

Dessa forma, o instrumento alimenta o processo fenomenológico para busca do dado/registro qualitativo do fenômeno e sua descrição dentro de seu contexto espaçotemporal. Esses registros possibilitarão a visão do 'todo' (HOLANDA, 2003) acerca desses educandos, materializada na avaliação pedagógica e sistematizada no Plano de Trabalho Pedagógico de cada um deles.

Em um segundo passo, a partir dos dados descritos pelo professor, para epoché/redução fenomenológica, devem-se realizar várias leituras, procurando identificar unidades de significado, ou seja, aquilo que é próprio do sujeito/educando, "a representação mental dos fenômenos abordados de acordo com as experiências vividas, isto é, o vivido do sujeito clarificado pela relação" (HOLANDA, 2003, p.61).

Em outro momento, um professor relata o caso de um educando, com comportamento introvertido e pouco verbal, encaminhado para o AEE na área de desenho, derivada de sua habilidade identificada em sala de aula, inicialmente. Contudo, em seu primeiro encontro, percebeu que ele estava vestido com uma camisa de um personagem dos quadrinhos.

Com base na busca de elementos significativos, indicamos a elaboração da Versão de sentido, que seria o acompanhamento de expressões, de características peculiares, ou seja, como o educando vê/percebe suas experiências, cabendo ao professor captar/intuir os sentidos que integram essas experiências. Segundo Holanda (2003, p.56), "trata-se de 
uma elaboração entre a linguagem do depoente, a formulação geral do pesquisador e a subsequente colocação dos pontos de uma forma geral".

Assim, a partir da experiência retratada pelo docente, e na elaboração da Versão do sentido, é possível elencar que a identificação com personagens expressam muito sobre nós. Não se trata ali de uma simples camisa, mas um dado que evidencia possibilidades de conhecer o educando em certas particularidades. Desta forma, por que não iniciar uma conversa a partir daquele personagem? Seu resultado será (provavelmente) uma Versão de Sentido.

Um outro encontro foi sucedido de falas dos professores acerca dos mitos e realidades imaginárias criadas acerca do aluno com AH/SD. Neste sentido, alguns deles próprios externaram que também possuíam apriorismos e, que isto gerava sentimentos de angústia, uma vez que havia um abismo entre o real e o "esperado".

Questionando acerca de suas abordagens iniciais com os educandos, percebemos que eles traziam consigo repertório diretivo e indutivo a certas respostas. Neste sentido, apresentamos que na fenomenologia não se pressupõe hipóteses.

Desta forma, uma pesquisa/intervenção baseada em seus pressupostos deve se iniciar por comportamentos não-diretivos, sobretudo nos primeiros contatos. Assim, indicamos o uso de conversas informais não diretivas, tendo como ensejo o conhecimento do educando como ele é. Exemplificando: Imagine que o educando possui interesse por arte barroca. Para os professores especializados, abrem-se possibilidades de vivências com o educando, a partir disso, favorecendo 'o processo de descoberta de sua própria humanidade' (HOLANDA, 2003).

Instrumentos como estes podem auxiliar aos professores no processo de desvelamento da essência do fenômeno que, em casos específicos como estes, são as habilidades a serem desenvolvidas nos educandos a partir de seus interesses de sentido/existenciais, bem como, a sua identificação a partir de comportamentos que favoreçam a abertura para sua percepção/compreensão.

Apresentadas algumas das contribuições da fenomenologia ao trabalho do professor especializado, é necessário destacarmos que a utilização desses procedimentos, seja na compreensão/desvelamento/identificação dos educandos nas AH/SD, seja nos projetos de 
enriquecimento curricular, é propiciadora de aporte teórico potencializador de espaçostempos orgânicos ${ }^{13}$ de bem estar.

Por último, é necessário externar que, nessas relações e trocas de experiências, desvelam-se as peculiaridades e idiossincrasias de cada educando nas AH/SD e, dessa forma, favorecidos pelos preceitos do papel da percepção, o professor especializado pode ser beneficiado nos entrelaçamentos e compreensão de seus educandos, a partir do olhar sobre o experienciado, cujo registro de depoimentos e comportamentos alimentará a compreensão eidética do vivenciado (HOLANDA, 2003).

\section{Considerações Finais}

O ingresso no Curso de Mestrado Profissional em Educação, após anos de uma caminhada no trabalho, construiu minha relação com a Fenomenologia deslocando-me para caminhos distintos aos usualmente utilizados em minha vida. Nesse espaço-tempo atual, no qual a pesquisa integra etapa de formação, volto-me para a realidade profissional sobre a égide compreensiva/ transformadora.

Com a temática das $\mathrm{AH} / \mathrm{SD}$, iniciei imersões, com vieses metodológicos da Fenomenologia, em autores que a compreendem numa perspectiva psicológico/educacional, fato que serviu como amparo particular para uma psicóloga/professora/assessora que vem atuando na área da educação. Assim, beber nessas fontes ofertou novos sentidos ao meu projeto de pesquisa e me sorveu outros atravessamentos como sujeito carnal, em um tempo e espaço no mundo humano, marcando o meu existir.

Desde então, o projeto deixou de ser o ser eu-no mundo para se transformar em ser o ser com-no mundo. Ou seja, promoveu outros encontros/relações e agregou novos atores/seres, propiciando vivências e experiências, com o intuito de elaborar ciência, definida como conjunto de proposições na experiência imediata com o outro.

Desta forma, este artigo é consequência de minha incursão pela fenomenologia, que atualmente transponho para minhas práticas pedagógicas. É a partir desse sentimento que percebo a necessidade da compreensão dos educandos em aspectos multidimensionais; numa demonstração de que é necessário entendê-los qualitativamente como indivíduos, em suas particularidades, pois apenas uma atitude aberta por parte dos educadores pode

\footnotetext{
${ }^{13}$ Que estão em transformação de acordo com as necessidades.
} 
favorecer a inclusão escolar.

Neste sentido, acreditamos ter alcançado nosso objetivo neste trabalho, em que, apresentamos contribuições do método fenomenológico para o professor do AEE nas $\mathrm{AH} / \mathrm{SD}$, em diálogos vivenciais e teórico-metodológicos, constituindo-se no desvelamento da experiência fenomenológica eidética, encarnada e desnudada a partir da expressão do vivido.

Em termos de prospectivas futuras, pretendemos fomentar outras formações que possam possibilitar o conhecimento do professor dos instrumentos e práticas do método fenomenológico para identificação de AH/SD, e desta forma, desvelar possibilidades interventivas desconstrutoras de modelos cognitivistas tão arraigados à área.

Baseado nesses preceitos, o trabalho do professor especializado com educandos nas $\mathrm{AH} / \mathrm{SD}$, enriquece-se com infinitas possibilidades de existir-no-mundo, uma vez que, para saber quem se é, precisa-se, de certo modo, saber onde se está e com quem se encontra, pois a identidade de cada um está implicada/imbricada nos acontecimentos que ele vivencia.

\section{Referências}

ALENCAR, Eunice Maria L. Soriano; FLEITH, Denise Souza. Superdotados: determinantes, educação e ajustamento. 2. ed. rev. ampl. São Paulo: EPU, 2001.

AMATUZZI, Mauro Martins. Por uma psicologia humana. São Paulo: Alínea, 2010.

BOCK, Ana Mercês Bahia; FURTADO, Odair; TEIXEIRA, Maria de L. T. A evolução da ciência psicológica. In: Psicologias: uma introdução ao estudo de psicologia. 13. ed. São Paulo: Saraiva, 2002. p. 39- 56. Cap. 2.

BRASIL. Ministério da Educação. Política Nacional de Educação Especial na Perspectiva Inclusiva. Brasília, DF, 2008.

BRUNS, Maria Alves de Toledo. A redução fenomenológica em Husserl e a possibilidade de superar impasses da dicotomia subjetividade-objetividade. In: BRUNS, Maria Alves de Toledo; HOLANDA, Adriano Furtado (Org.). Psicologia e fenomenologia: reflexões e perspectivas. Campinas: Alínea, 2003. p. 65- 75

FLEITH, Denise de Souza (Org.). A construção de práticas educacionais para alunos com altas habilidades/superdotação. v. 1,2, 3. Brasília: Ministério da Educação, Secretaria de Educação Especial, 2007. 
FORGHIERI, Yolanda Cintrão. A fenomenologia e suas relações com a psicologia. In: . Psicologia fenomenológica: fundamentos, métodos e pesquisa. São Paulo: Pioneira Thomson Learning, 2004. p.13- 22. Cap. 2.

FRAGA, Maria Amélia Barcellos; FREITAS, Sumika Soares. Inteligência, criatividade e superdotação: contribuições da perspectiva histórico-cultural. Revista Educação Especial em Debate, Universidade Federal do Espírito Santo, Núcleo de Ensino Pesquisa e Extensão (NEESP), Centro de Educação, ano 1, v. 1, n. 2, p. 131- 146, jul./dez. 2016.

GOMES, Vitor. A contribuição de Merleau-Ponty em pesquisas sobre o "eu" diferente. Revista da Faculdade de Educação, Universidade do Estado do Mato Grosso, ano 15, vol.28, n. 2, p. 181- 193, jul./dez. 2017.

GOMES, Vitor. A fenomenologia da resiliência: teorias e histórias de vida. Curitiba: CRV, 2016.

GOMES, Vitor. Introdução a uma psicopedagogia fenomenológica: a psicopedagogia fenomenológica e o humor resiliente nas histórias em quadrinhos: possibilidades de análise. São Paulo: Plêiade, 2012.

HOLANDA, Adriano Furtado. Pesquisa fenomenológica e psicologia eidética: elementos para um entendimento metodológico. In: BRUNS, Maria Alves de Toledo; HOLANDA, Adriano Furtado (Org.). Psicologia e fenomenologia: reflexões e perspectivas. Campinas: Alínea, 2003. p. 41-64.

MENDES, Enicéia Gonçalves. Sobre alunos "incluídos": reflexões sobre o conceito de inclusão escolar. In: VICTOR, Sonia Lopes; VIEIRA, Alexandro Braga; OLIVEIRA, Ivone Martins de (Org.). Educação especial inclusiva: conceituações, medicalização e políticas. Campos dos Goytacazes, RJ: Brasil Multicultural, 2018. p. 58- 81.

MERLEAU PONTY, Maurice Merleau. Fenomenologia da percepção. São Paulo: Martins Fontes, 2011.

NETO, João Cabral de Melo. Tecendo a manhã. In: Jornal de Poesia, 2006. Disponível em: http://www.jornaldepoesia.jor.br/joao02.html. Acesso em: 5 jun. 2018.

PEREZ, Suzana Graciela Pérez Barrera. A identificação das altas habilidades sob uma perspectiva multidimensional. Revista Educação Especial. Universidade Federal de Santa Maria. v. 22, n. 35, p. 299- 328, set./dez. 2009. Disponível em: http://www.ufsm.br/revistaeducacaoespecial. Acesso em: 5 fev. 2014.

RENZULLI, Joseph. Modelo de enriquecimento para toda a escola: um plano abrangente para o desenvolvimento de talentos e superdotação. Revista "Educação Especial. Universidade Federal de Santa Maria. v. 27, n. 50, p. 539- 562, set./dez. 2014. Disponível em: http://www.ufsm.br/revistaeducacaoespecial. Acesso em: $\operatorname{mar} / 16$ 
RANGNI, Rosemeire de A; COSTA, Maria da Piedade Resende da. A educação dos superdotados: história e exclusão. Revista Educação, Universidade de Guarulhos, ano 18, v. 6, n. 2, p. 16- 24, $2011 . \quad$ Disponível em: http://revistas.ung.br/index.php/educacao/article/viewFile/923/903. Acesso em: 10 maio. 2018

VIRGOLIM, Ângela Maria R. Encorajando potencialidades: desenvolvendo a superdotação na teoria e na prática. In: Altas habilidades/ superdotação: encorajando potenciais. Brasília: Ministério da Educação, Secretaria de Educação Especial, 2007. p. 51- 71. Cap. 4

VIRGOLIM, Ângela Maria R. A construção de práticas educacionais para alunos com altas habilidades/superdotação. In: Encontro Nacional do Conselho Brasileiro para Superdotação, 4. Congresso Internacional sobre Altas Habilidades/ Superdotação, 1.; Seminário sobre Altas Habilidades/ Superdotação da UFPR, 2010, Curitiba. Anais eletrônicos... Disponível em: http://portal.mec.gov.br/index.php?option=com_content\&view=article\&id=12679\%3A a-construcao-de-praticaseducacionais-para-alunos-com-altashabilidadessuperdotacao\&catid=192\%3Aseesp-esducacao-. Acesso em: 5 jul. 2014.

ZAIA, Priscila; NAKANO, Tatiana Cássia; PEIXOTO, Evandro Morais. Scale for identification of characteristics of giftedness: internal structure analysis. Estudos de Psicologia, Campinas, v. 35, m. 1, p. 39- 51, 2018. Disponível em: https://doi.org/10.1590/1982-02752018000100005. Acesso em: 21 jun. 2018.

\section{Correspondência}

Maria Amelia Barcellos Fraga - Universidade Federal do Espírito Santo. Av. Fernando Ferrari, 514 - Goiabeiras, Vitória. CEP: 29075-910. Vitória, Espírito Santo, Brasil.

This work is licensed under a Creative Commons Attribution-NonCommercial 4.0 International (CC BY-NC 4.0) 